\title{
Queimadura por soda cáustica
}

Caustic soda chemical burn

Sidney Zanasi Jr, Gerson Vilhena Pereira Filho, Alessandra Giammarusti Watase, Rafael Zacarias Batista, Maurício Orel, Edric Rabelo Brianezi, Luis Felipe Conti Teixeira

\section{Resumo}

No Brasil, estatísticas mostram que de 1 a $4 \%$ das queimaduras são provocadas por agentes químicos, sendo a soda cáustica um dos principais causadores deste tipo de queimadura. 0 presente trabalho traz um relato de caso no qual um paciente com queimaduras por soda cáustica foi atendido no Centro Hospitalar de Santo André (SP). Foi submetido à hidratação endovenosa, hidroterapia, analgesia, vacina antitetânica e curativo nas lesões. Segundo estatísticas americanas, $50 \%$ dos casos de queimaduras químicas se associam a acidentes de trabalho, 30\% estão relacionados a acidentes domésticos e $20 \%$ são ocasionados por agressão. A diferença entre queimaduras químicas e aquelas que resultam de outros mecanismos é que o processo lesivo ocasionado pela queimadura química persiste até que o efeito do agente seja neutralizado. Portanto, o tratamento em caso de queimadura química também difere do administrado à queimadura térmica. A medida clínica mais recomendada é a hidroterapia devido a sua eficiência em relação à melhora no prognóstico do paciente. Desbridamento de tecido necrótico, enxertia de pele ou retalhos são medidas utilizadas juntamente com a hidroterapia, cada qual dependendo da severidade das lesões.

Unitermos: Queimadura química; soda cáustica; hidroterapia.

\section{Abstract}

Brazilian statistics show that 1 to $4 \%$ of burns are caused by chemical substances. Caustic soda is one of the main substances causing this kind of burn. The study presents a case report in which a man was burned by caustic soda. He was treated at the Centro Hospitalar de Santo André - SP and submitted to hydration, analgesia, antitetanic vaccination and wound dressing. According to American statistics $50 \%$ of chemical burns are work-related accidents, $30 \%$ are associated to accidents at home and $20 \%$ are assaults. The difference between chemical burns and thermal burns is that the destructive process occasioned by chemical burns continues until the effect of the cauterizing agent is neutralized. Therefore, the treatment of chemical burns is also different from thermal burns. The most recommended clinical management is hydrotherapy due to its efficiency, which is related to a better prognosis of the patient. The debridement of necrotic tissue, skin grafting and antibiotic prophylaxis are the applied management in addition to the hydrotherapy, depending on the degree of the wound.

Keywords: Chemical burn; sodium hidroxide; hydrotherapy.

Recebido: 23/11/2007

Revisado: $23 / 01 / 2008$

Aprovado: 31/01/2008 


\section{Introdução}

As queimaduras químicas causadas por soda cáustica são pouco freqüentes, porém existem peculiaridades em seu tratamento que devem ser consideradas. A maior parte dos protocolos de tratamento para queimaduras são baseadas nas queimaduras térmicas. No entanto, existem diferenças entre queimaduras térmicas e por álcalis. Estatísticas americanas demonstram que dos 60 mil pacientes que procuram atendimento médico por queimadura, 4 a $5 \%$ são por queimaduras químicas, sendo $25 \%$ provocadas por agentes alcalinos ${ }^{1}$. Segundo estatísticas brasileiras, as queimaduras químicas correspondem de 1 a $4 \%$ das queimaduras de várias etiologias, com aproximadamente $36 \%$ de letalidade ${ }^{2}$.

O presente estudo tem como objetivo relatar um caso clínico e revisar a literatura sobre queimaduras químicas causadas por álcalis.

\section{Relato de caso}

W.O.P., masculino, 43 anos, branco, vítima de agressão por soda cáustica líquida. Deu entrada no Pronto Socorro do Centro Hospitalar do Município de Santo André, SP, referindo dor intensa nos locais das queimaduras. Ao exame, o paciente apresentava queimaduras de segundo e terceiro graus em hemiface direita, região cervical direita, terço superior de ambos os hemitórax e membro superior direito, totalizando cerca de 18\% de superfície corpórea queimada (Figura 1). Negava tratamento prévio das lesões até a sua chegada ao hospital, com aproximadamente 30 minutos de intervalo. O paciente foi atendido inicialmente conforme a sistematização sugerida pelo Advanced Trauma Life Support (ATLS), sem apresentar lesões que o colocassem em risco imediato de vida. Após o atendimento inicial, foi submetido à hidratação intravenosa, analgesia, vacina antitetânica, hidroterapia por 30 minutos sob água corrente e curativo oclusivo com sulfadiazina de prata. Evoluiu sem alterações hidroeletrolíticas, porém com piora das lesões tanto em profundidade como em extensão.
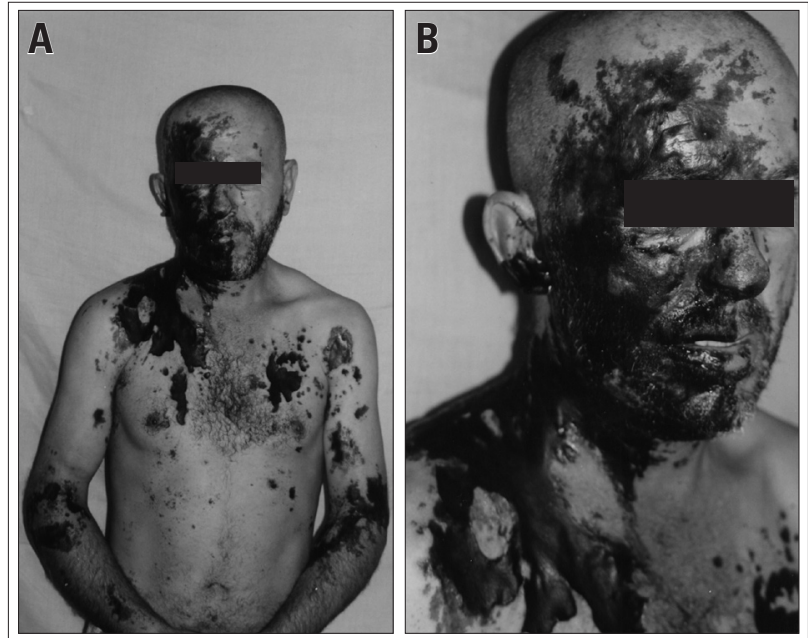

Figura 1 - Queimadura após 12 horas da chegada no Pronto Socorro; A) Visão frontal. B) Visão antero-lateral.
Com 72 horas de evolução, iniciaram-se sucessivos desbridamentos tangenciais dos tecidos desvitalizados e curativos com desbridantes químicos, visando o preparo do leito receptor para enxertia de pele (Figura 2). Após um período de seis dias, foi realizada enxertia de pele parcial e total, conforme a região acometida.

Não houve complicações no ato cirúrgico e no pós-operatório imediato. O paciente recebeu alta hospitalar no vigésimo-sexto dia de internação, com evolução satisfatória das lesões.

Como tratamento complementar foram utilizadas malhas compressivas nas áreas queimadas, na tentativa de diminuir seqüelas cicatriciais. Apesar disso, o paciente evoluiu com cicatrização patológica em algumas áreas como por exemplo, na cavidade oral. Nas Figuras 3 e 4 podemos observar o resultado após um ano do tratamento inicial. Depois desse período, o paciente abandonou o acompanhamento, não tendo então, a oportunidade de ser operado para corrigir as seqüelas.

\section{Discussão}

Os álcalis formam a segunda categoria mais freqüente a gerar queimaduras químicas, sendo o hidróxido de sódio (soda cáustica) o agente etiológico mais freqüente desse grupo. Segundo dados norte-americanos, acidentes de trabalho correspondem a $50 \%$ dos casos de queimados por agentes químicos, seguido de acidentes domésticos com $30 \%$ e agressão com $20 \%$ dos casos $^{1}$.

As queimaduras por álcalis penetram mais profundamente na pele quando comparadas com queimaduras térmicas ou por ácidos. O mecanismo de lesão tissular pelos álcalis compreende três fatores: (1) desidratação celular intensa, (2) saponificação da gordura (que gera a perda do isolamento térmico do corpo), (3) inativação das proteínas enzimáticas que, paralelamente, formam ligações com o álcali, originando os proteinatos em uma reação exotérmica, o que agrava ainda mais a lesão inicial. Esses proteinatos são solúveis, permitindo sucessivas transferências do íon $\mathrm{OH}$, acometendo grande extensão de lesão tecidual ${ }^{3}$.
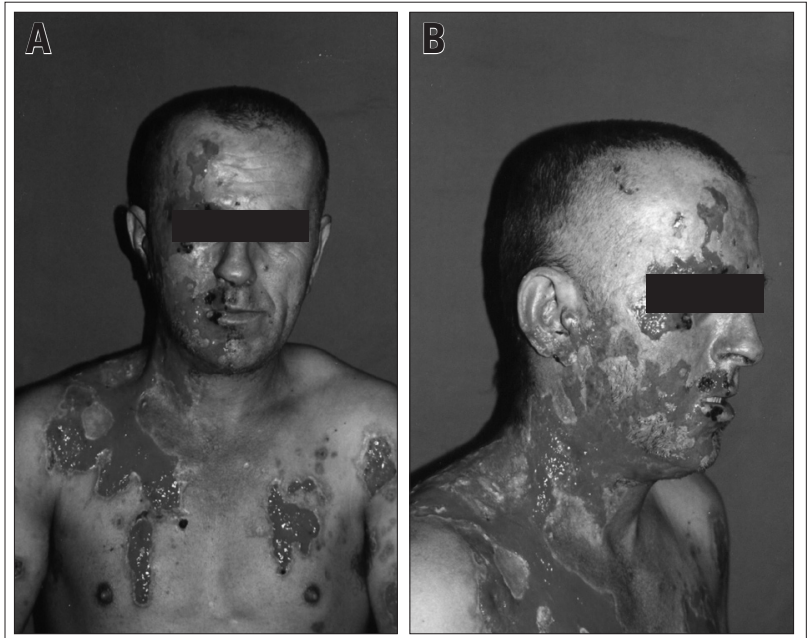

Figura 2 - Após excisões tangenciais, seis dias após o trauma: A) Visão frontal; B) Visão ântero-lateral. 


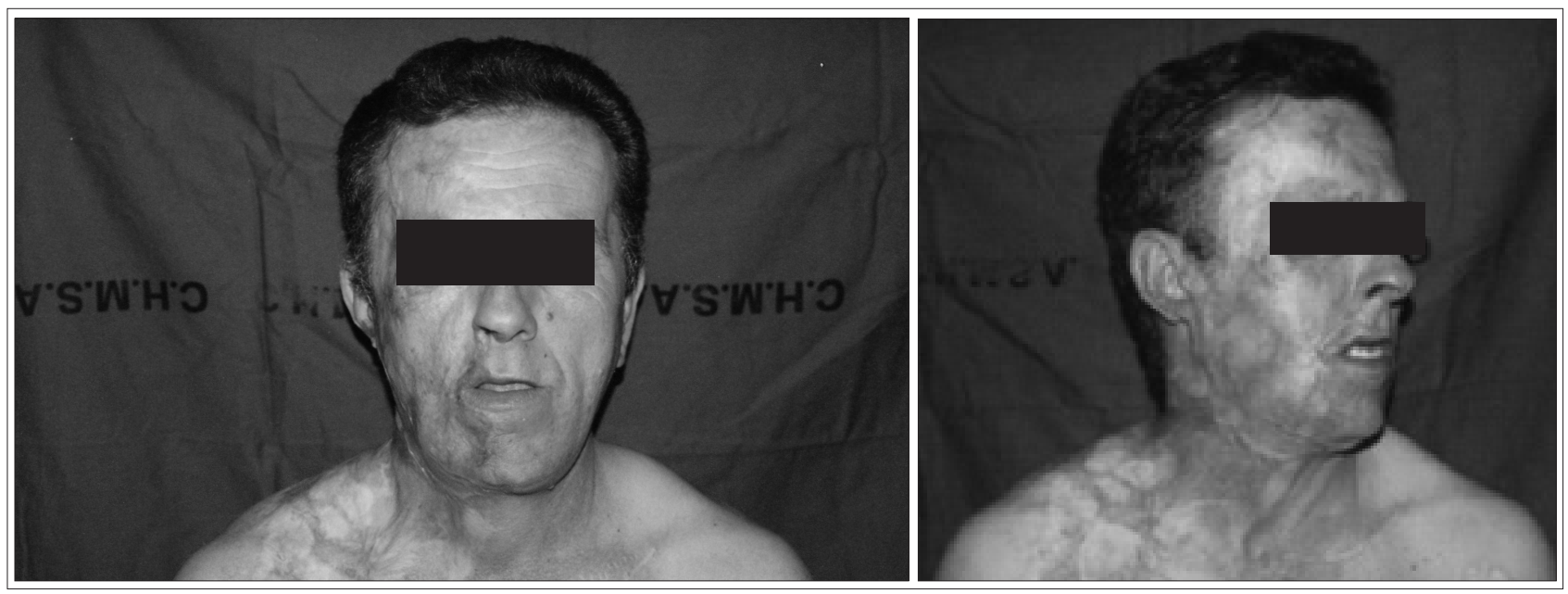

Figura 3 - Resultado após aproximadamente um ano da enxertia de pele: A) Visão frontal; B) Visão ântero-lateral. Nota-se brida em região cervical lateral direita.

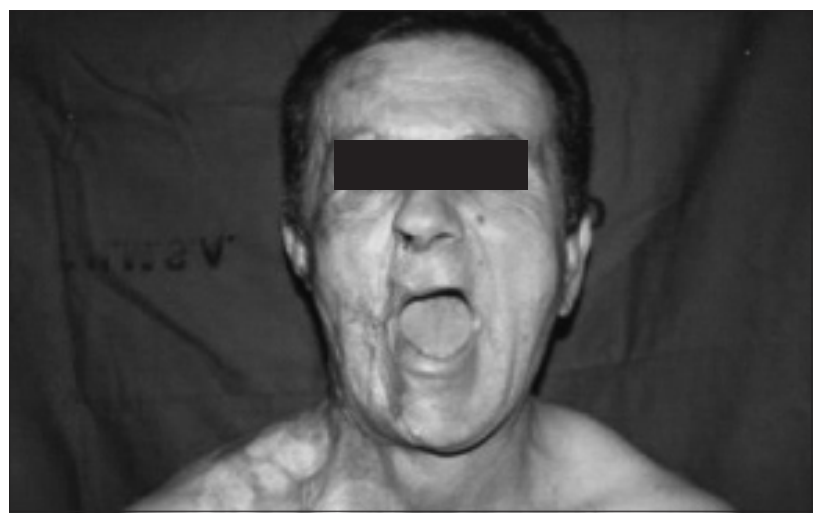

Figura 4 - Visão frontal com abertura oral após aproximadamente um ano da enxertia de pele. Nota-se seqüela de comissura bucal à direita.

Estes íons geram novas reações químicas, penetrando mais profundamente nos tecidos e limitando seu contato com diluentes, como a água, por exemplo. A seguir, há decréscimo do conteúdo de colágeno dos tecidos e saponificação dos lipídes da membrana celular, caracterizando processo de necrose liquefativa ${ }^{1}$.

É gerado um pH álcali no meio tecidual, favorecendo a infecção bacteriana secundária. Devido a este fato, nosso paciente teve progressão das lesões, necessitando de sucessivos desbridamentos, porém sem infecção aparente.

O álcali, devido a sua grande capacidade de penetração, tende à cronicidade da lesão pela dificuldade de eliminação do agente, sendo comum a necessidade de vários desbridamentos tangenciais até se alcançar um tecido viável. A queimadura induzida pelos álcalis pode gerar perda total da espessura da pele, geralmente destruindo seus anexos e tornando o tecido enegrecido em um curto período de tempo, conforme observado em nosso paciente já na admissão no pronto socorro.

Diferentemente das queimaduras por outros agentes, cuja lesão tissular se estabiliza mais precocemente, a destruição celular pelos álcalis continua até que estes sejam removidos ou diluídos. Em geral, a severidade da lesão celular é proporcional à concentração da substância, à duração da exposição, à área do organismo afetada e à extensão da penetração do álcali.

Sabendo-se o percentual da concentração ou do pH da substância alcalina, pode ser estimado o grau da dor e da profundidade da lesão. Substância alcalina com mais de $1 \%$ de concentração ou pH maior que 11,5 acarreta em lesões irreversíveis. Concentrações entre 25 e 50\% de soda cáustica resultam em irritação na pele em três minutos. Em contrapartida, a mesma solução a $4 \%$ causa uma irritação subjetiva somente após horas. Logo, exposição a baixas concentrações de soda cáustica leva a uma lesão mais severa, devido a uma sintomatologia quase que imperceptível após o contato imediato ${ }^{1}$.

Após o tratamento inicial, a medida clínica que apresenta melhores resultados finais em relação ao prognóstico do paciente é a hidroterapia. Estudos evidenciam que a lavagem com água é um fator determinante para minimizar o grau da lesão, sobretudo dentro do período de uma hora após a exposição ao álcali ${ }^{4}$.

O tratamento principal para queimaduras por álcalis, após o atendimento inicial e suporte clínico, é a associação de hidroterapia exaustiva com desbridamento dos tecidos necróticos e enxertias de pele ou retalhos. Persistem ainda controvérsias sobre o tempo ideal do início do tratamento cirúrgico.

Outro assunto a ser abordado consiste no uso de agentes neutralizadores químicos. Davidson ${ }^{5}$ constatou, experimentalmente em cães, que estes sobreviviam mais quando tratados com hidroterapia do que com agentes neutralizadores, uma vez que esses agentes ocasionam maiores reações exotérmicas, lesando ainda mais os tecidos. Na hidroterapia, também pode ocorrer reação exotérmica, porém esta é minimizada atenuando-se o calor com o uso de grande volume de água. Em uma série de 273 pacientes, nos quais foi administrada lavagem com água sob chuveiro, o pH cutâneo praticamente normalizou após uma hora de irrigação. $\mathrm{O}$ uso imediato da hidroterapia diminui o tempo de hospitalização, o tempo para a realização de enxertia de pele e o número de casos que necessitam de cirurgia ${ }^{6}$. 
Após a retirada das vestes do paciente e de todas as partículas sólidas visíveis, as lesões devem ser irrigadas de seis horas a seis dias, com água corrente em baixa pressão, à temperatura agradável ao paciente e com descansos de 15 minutos por hora. Deve-se tomar especial atenção para evitar a hipotermia, uma vez que o álcali quebra a barreira térmica ao destruir as camadas lipídicas. O agravante está no fato da hipotermia ser uma das causas determinantes para a piora clínica do paciente. O uso da lavagem pré-hospitalar, no mesmo local do acidente, tem demonstrado diminuição na incidência de queimaduras de terceiro grau, acarretando menor morbidade. A hidroterapia deve ser realizada mesmo que o paciente procure ajuda tardiamente.

A queimadura por álcali pode determinar alcalose metabólica, insuficiência respiratória e insuficiência renal. A hidratação do paciente deve ser calculada conforme a superfície corpórea afetada, utilizando-se das fórmulas habituais e dos parâmetros hemodinâ- micos do paciente. Enquanto as queimaduras por ácidos tendem a causar lesões mais superficiais na pele, exigindo menor correção volêmica, nas queimaduras por álcalis ocorre o inverso. Após a remoção do produto químico, a pele lesada deve ser protegida contra o risco de infecção, já com os tecidos inviáveis desbridados e o acetato de mafenide aplicado topicamente. Além de ser bacteriostático, este forma com os resíduos de soda cáustica, acetato de sódio e radicais de mafenide, que são inócuos para os tecidos. A sulfadiazina de prata também pode ser usada.

Antiobioticoprofilaxia sistêmica é desnecessária e deletéria devido à seleção de flora bacteriana com cepas resistentes.

A literatura sugere o desbridamento tangencial precoce dos tecidos necróticos ou afetados pelos cáusticos, com posterior enxertia cutânea ou retalhos a depender da área afetada, para obtenção de melhores resultados.

\section{Referências}

1. Lorette $\mathrm{JJ} \mathrm{Jr}$, Wilkinson JA. Alkaline chemical burn to the face requiring full-thickness skin grafting. Ann Emerg Med 1988;17(7):739-41.

2. Gomes DR, Serra MC, Macieira Jr L. Condutas atuais em queimaduras. Rio de Janeiro: Revinter; 2001. p. 117-22.

3. Lewis GK. Chemical burns. Am J Surg 1959;98(6):928-37.
4. Gruber RP, Laub DR, Vistnes LM. The effect of hydrotherapy on the clinical course and pH of experimental cutaneous chemical burns. Plast Reconstr Surg 1975;55(2):200-4.

5. Davidson EC. The treatment of acid and alkali burns: an experimental study. Ann Surg 1927;85(4):481-9.

6. Bromberg BE, Song IC, Walden RH. Hydrotherapy of chemical burns. Plast Reconstr Surg 1965;35:85-95. 